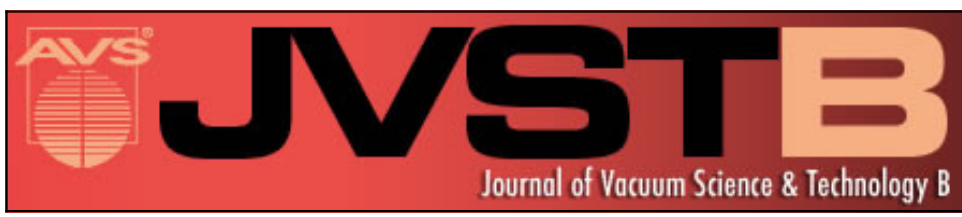

Study of the effect of thermal treatment on morphology and chemical composition of silicon-on-insulator

Prabhava S. N. Barimar, Catherine M. Doyle, Borislav Naydenov, and John J. Boland

Citation: Journal of Vacuum Science \& Technology B 34, 041806 (2016); doi: 10.1116/1.4955067

View online: http://dx.doi.org/10.1116/1.4955067

View Table of Contents: http://scitation.aip.org/content/avs/journal/jvstb/34/4?ver=pdfcov

Published by the AVS: Science \& Technology of Materials, Interfaces, and Processing 


\title{
Study of the effect of thermal treatment on morphology and chemical composition of silicon-on-insulator
}

\author{
Prabhava S. N. Barimar, Catherine M. Doyle, Borislav Naydenov, and John J. Boland ${ }^{\text {a) }}$ \\ CRANN, School of Chemistry, Trinity College Dublin, Dublin, D2, Ireland
}

(Received 9 April 2016; accepted 3 June 2016; published 1 July 2016)

\begin{abstract}
Removing the ultrathin native oxide layer from silicon-on-insulator (SOI) without damaging the Si device layer poses several processing challenges, the main one being the maintenance of the device layer integrity during oxide layer removal. In order to address this challenge and find a low thermal budget process, the thermal decomposition of the ultrathin native oxide in ultrahigh vacuum has been investigated using scanning electron microscopy, atomic force microscopy, scanning tunneling microscopy, and x-ray photoelectron spectroscopy. The evolving morphology and chemical composition of the ultrathin oxide and the SOI device layer were investigated as a function of anneal temperature and duration. Multiple anneal cycles at $750{ }^{\circ} \mathrm{C}$, each lasting for $30-90 \mathrm{~s}$, was found to be an effective method of desorbing the oxide without causing dewetting of the device layer. The total amount of carbon present on the sample was not altered significantly by thermal treatment; however, a change in the chemical composition of the carbon was noted. A simple oxygen plasma-based ex situ cleaning step before annealing was found to be effective in reducing the density of $\mathrm{SiC}$ on the annealed sample while keeping the annealed surface atomically smooth. (C) 2016 American Vacuum Society. [http://dx.doi.org/10.1116/1.4955067]
\end{abstract}

\section{INTRODUCTION}

Silicon-on-insulator (SOI), a thin silicon film on top of an insulating layer of buried oxide (BOX) atop a bulk Si wafer, is of fundamental scientific interest as the confinement of the electrons in the thin Si device layer may lead to different mechanical, electronic, and thermodynamic properties compared to those of bulk $\mathrm{Si}^{1}{ }^{1} \mathrm{SOI}$ is also of technological interest to the semiconductor industry as it offers a possible means to achieve improved device performance. ${ }^{1,2}$

In situ preparation of $\mathrm{Si}$ samples in $\mathrm{UHV}$ is usually accomplished via thermal annealing. This process removes the native oxide from the sample, resulting in an atomically clean surface. Oxide desorption has been studied in detail for bulk Si samples. ${ }^{3-10}$ The mechanism for the desorption has been identified as the creation of $\mathrm{Si}$ adatoms which then diffuse on the surface and react with $\mathrm{SiO}_{2}$ to produce $\mathrm{SiO}$ via the equation $\mathrm{Si}+\mathrm{SiO}_{2} \rightarrow 2 \mathrm{SiO}^{6,10}$ The silicon monoxide then sublimes from the surface. ${ }^{8}$ Hence, voids in the oxide are formed around $\mathrm{Si}$ adatom sites, and as the above reaction occurs at the edges of voids, these oxide-free regions (OFRs) increase in size, eventually overlapping with adjacent OFRs, exposing atomically clean $\mathrm{Si}$ beneath. ${ }^{8}$ While the literature contains many reports of this oxide desorption from bulk $\mathrm{Si}$, to our knowledge, there is only one brief report of a similar process occurring on SOI. ${ }^{11}$

Thin films are also susceptible to a phenomenon known as "dewetting," whereby the film agglomerates into small islands in order to minimize surface energy, exposing the underlying low surface energy BOX layer. Once the native oxide has been removed from the SOI, the Si device layer exhibits dewetting behavior under certain thermal conditions, peeling back to uncover the BOX. There are many

${ }^{a)}$ Electronic mail: jboland@tcd.ie literature reports of such dewetting occurring for SOI device layers. ${ }^{11-18}$ The phenomenon has been modeled as a fivestage process: (1) a void is formed in the thin film, with a radius greater than a critical radius that depends on film thickness, (2) the void edge thickens and then retracts, exposing the underlying BOX, (3) the thickened void edge breaks down due to a Rayleigh instability, (4) the void edge forms uniformly spaced fingers of $\mathrm{Si}$, and (5) these fingers break up into $\mathrm{Si}$ islands via a second Rayleigh instability. ${ }^{12}$ Dewetting has been observed for SOI films at temperatures higher than $800{ }^{\circ} \mathrm{C} .{ }^{14,17}$ The recognized procedure for in situ cleaning of bulk $\mathrm{Si}$ in $\mathrm{UHV}$ involves heating the $\mathrm{Si}$ to temperatures of approximately $1200{ }^{\circ} \mathrm{C} ;{ }^{19}$ therefore, an alternative method of removing the oxide from SOI must be used in order to avoid dewetting of the device layer. ${ }^{1}$

In the present work, oxide desorption from the $\mathrm{Si}(100) \mathrm{SOI}$ device layer has been studied in greater detail than previously reported. ${ }^{11}$ In particular, low thermal budget processes were investigated in order to facilitate oxide removal while avoiding dewetting of the device layer. The effects of multiple anneal cycles of varying duration at $750{ }^{\circ} \mathrm{C}$ were studied and compared with longer anneals at 690 and $750{ }^{\circ} \mathrm{C}$. The resultant oxide desorption and surface morphology were studied using SEM and AFM. Dewetting of the SOI device layer under some thermal processing conditions is also discussed. The effect of thermal treatment on the SOI was studied via AFM, STM, and angle-dependent $\mathrm{x}$-ray photoelectron spectroscopy (XPS) measurements of the Si $2 p$ and C 1s core level regions. Preanneal cleaning steps were also investigated, with the aim of reducing the amount of carbon present on annealed SOI samples.

\section{EXPERIMENT}

All thermal treatments were performed in a UHV chamber with a base pressure of better than $1 \times 10^{-10}$ mbar. 
Highly doped n-type (phosphorous doping, $\sim 10^{19} \mathrm{~cm}^{-3}$ ) SOI with an initial $\mathrm{Si}(100)$ device layer thickness of $50 \mathrm{~nm}$ was studied. The buried oxide thickness was $130 \mathrm{~nm}$, while the native oxide thickness was between 1 and $2 \mathrm{~nm}$. A cross-sectional schematic of the SOI is shown in Fig. 1. All $50 \mathrm{~nm}$ SOI wafers were used as obtained without further cleaning. Samples were cut into standard size of $10 \times 5 \mathrm{~mm}$. Direct resistive heating was used for thermal treatment, and sample temperature during annealing was monitored with a thermocouple and resistance temperature detector. The temperature ramp time for the thermal treatment were fixed for all experiment while the hold time was varied. The experimental setup was such that a thermal gradient of $\sim 50{ }^{\circ} \mathrm{C}$ was present along the sample during annealing, allowing the different stages of oxide desorption to be studied on a single sample. ${ }^{8}$ The temperatures given in the text are those measured at the center of the sample. Multiple anneal cycles were adopted for some thermal treatments in order to avoid dewetting. Surface morphology was investigated postanneal, ex situ, using a Zeiss scanning electron microscope and Bruker atomic force microscope. SOI samples of $50 \mathrm{~nm}$ were also thinned using inductively coupled plasma (ICP) etching in the presence of $\mathrm{SF}_{6}$ and $\mathrm{CHF}_{3}$ to obtain a device layer thickness of approximately $25 \mathrm{~nm}$, in order to better study the dewetting phenomenon. All AFM measurements were performed in tapping mode with tip cantilever resonance frequency of around $300 \mathrm{kHz}$. Ex situ XPS measurements were carried out in a UHV chamber with a base pressure of better than $1 \times 10^{-9}$ mbar. Turnaround time between removal of samples from vacuum following thermal treatment and their introduction into the XPS chamber was approximately $20 \mathrm{~min}$. An aluminum anode $\left(K_{\alpha}=1486.7 \mathrm{eV}\right)$ was used as the $\mathrm{x}$-ray source. The measurements were carried out at three different angles, corresponding to near-normal and grazing incidence with respect to the analyzer, as well as an angle of intermediate incidence. A Shirley background was subtracted from each spectrum before the data were fitted with Voigt lineshapes. An Oxford Instruments ICP-100 system was used for oxygen plasma cleaning of SOI before loading into the UHV chamber for annealing. STM measurements were made using a Createc UHV low temperature STM (LT-STM) operated at liquid nitrogen temperatures.

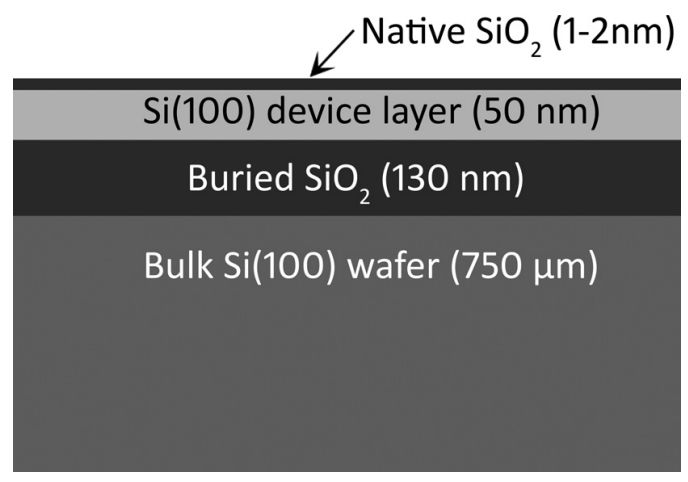

FIG. 1. Cross-sectional profile of the SOI used in this work.

\section{RESULTS AND DISCUSSION}

\section{A. Thermal desorption of oxide layer}

Figure 2 shows SEM data recorded at different points along a single SOI sample following ten anneal cycles at $750^{\circ} \mathrm{C}$, each of $60 \mathrm{~s}$ duration. The six images, labeled (a)-(f), show areas along the center of the sample moving from lower temperature end to higher, as indicated in the schematic shown in the inset of Fig. 2(a). The thermal gradient of approximately $50{ }^{\circ} \mathrm{C}$ from one end of the sample to the other facilitates the investigation of progressive oxide desorption using a single sample. The initial stages of oxide desorption are shown in Fig. 2(a). The lighter gray color signifies areas of native oxide, while the darker areas are OFRs, ${ }^{3,6,10}$ examples of latter are indicated in Fig. 2(a) with white arrows. The oxide desorption begins with the formation of voids in the ultrathin oxide film. ${ }^{7,20}$ Both the void formation and growth are sensitive to the varying morphology of the oxide film. ${ }^{7}$

The void propagation can be characterized by four stages: first, a Si monomer is formed in the void; second, the monomer diffuses on the surface until it reaches the Si/oxide interface at the void periphery; third, the Si monomer reacts with the oxide to form a $\mathrm{SiO}$ adsorbate; and finally, the $\mathrm{SiO}$ desorbs as a gas phase molecule. , $^{3,6,7,9,21}$

Figure 2(b) shows an area exposed to a higher temperature than that shown in Fig. 2(a). There are a greater number of OFRs in the area shown in Fig. 2(b), indicating that both the number and size of voids increase with annealing temperature. This is in agreement with previous reports where the number density of OFRs was found to increase during annealing. ${ }^{3,4,20}$

The OFRs shown in Fig. 2(b) have a roughly square shape with rounded edges, similar to voids reported in the literature. 4,6,22 They exhibit a range of sizes, indicating that OFRs were formed at different times during the experiment. While this may possibly be attributed to the fact that ten anneal cycles were used to heat the sample, with smaller OFRs having nucleated toward the end of the cycling process, there are reports in the literature of similar distributions of void size for continuous annealing. ${ }^{3,4}$ Hence, the presence of OFRs of different sizes may not be related to the use of cycling, but may instead indicate that OFR nucleation continues to occur throughout the duration of an anneal.

Figures 2(c) and 2(d) show the progression of the oxide desorption. The density of OFRs continues to increase with temperature. As each OFR increases radially in size, neighboring voids overlap and coalesce. In Fig. 2(d), oxide has been desorbed from more than $50 \%$ of the visible surface area, leaving some irregularly shaped oxide islands trapped atop Si pillars between adjacent voids, a phenomenon reported by Xue and coworkers. ${ }^{3}$ These oxide islands decrease in size as the oxide desorption continues [Fig. 2(e)].

The area shown in Fig. 2(f) is from the higher temperature side, which is the opposite end of the sample from that shown in Fig. 2(a). The oxide has been completely desorbed from this area; however, small protrusions are visible. These protrusions may also be seen clearly in Fig. 4(b). Two 


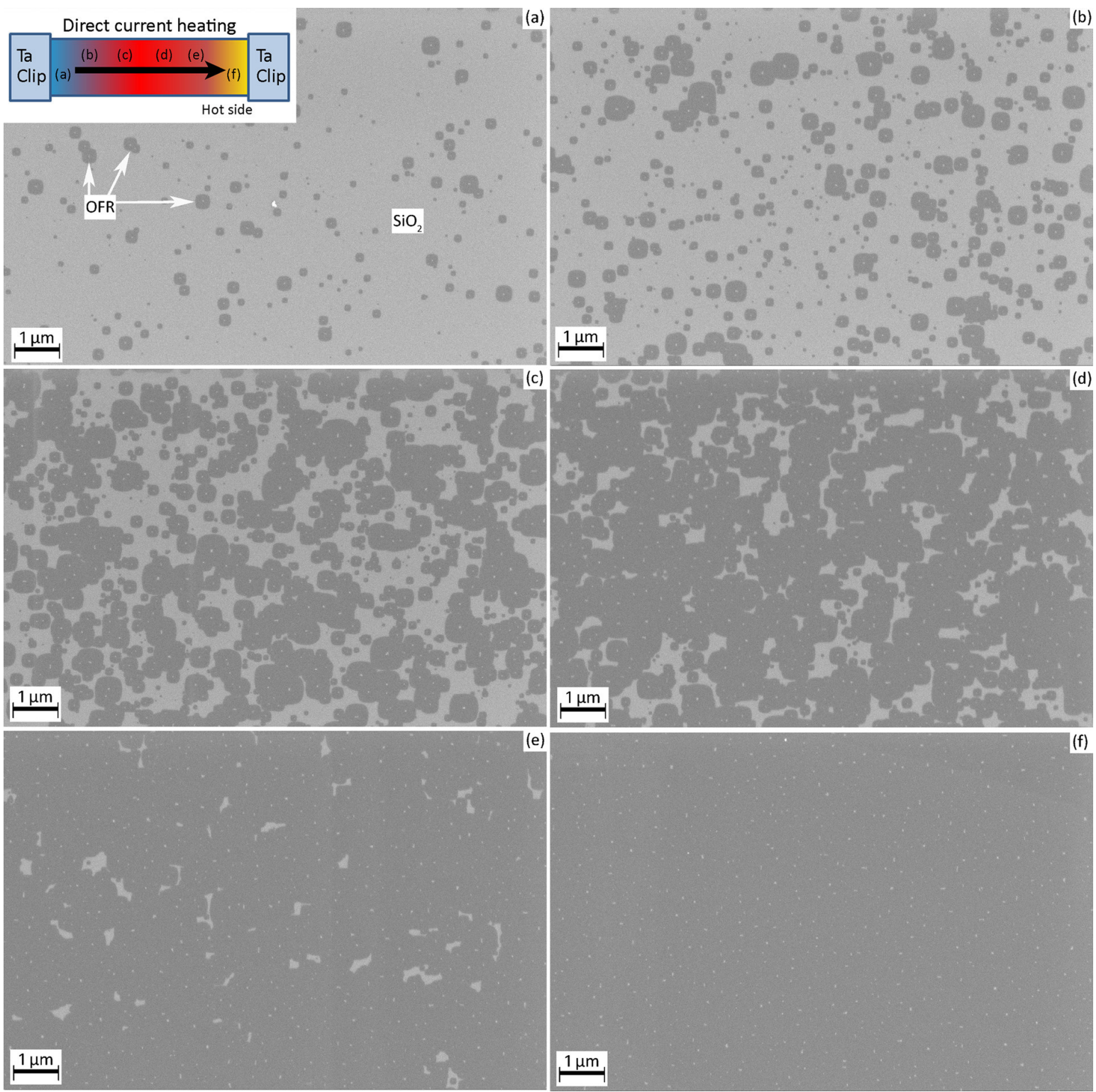

FIG. 2. (Color online) SEM images showing six different regions along the center of a $50 \mathrm{~nm}$ SOI sample after annealing at $750{ }^{\circ} \mathrm{C}$, ten cycles of $60 \mathrm{~s}$ duration. Inset in (a) shows positions of each area shown in (a)-(f).

alternate explanations for these protrusions are supplied in the literature. One proposal is that the protuberances are the surviving $\mathrm{SiC}$ islands that acted as nucleation sites for the OFRs, ${ }^{3,22}$ while the second is that they are remaining oxide islands that developed as neighboring voids connected. The latter explanation follows on from the observation that the OFRs become deeper as well as wider as they expand. $3,7,22$ When two adjacent voids overlap and continue to grow, a vertical distance of up to four ${ }^{3}$ or five ${ }^{7}$ atomic layers may be present between the bottom of the void and an oxide island trapped atop a Si pillar between the frontiers of two OFRs. Hence, it is energetically unfavorable for silicon monomers from the base of the void to react with $\mathrm{SiO}_{2}$ at the top of the pillar to form gaseous $\mathrm{SiO}$, thus leaving behind oxide islands surrounded by clean $\mathrm{Si}^{3}$ From the data presented in Fig. $2(\mathrm{f})$, it is not possible to determine which proposal is the most likely, but this issue will be addressed in more detail below.

In order to investigate the relationship between anneal duration and temperature, the anneal parameters were varied. Figure 3 shows SEM images recorded from a sample that has been subjected to ten anneal cycles at $750^{\circ} \mathrm{C}$, each lasting 30 s. Figure 3(a) shows an area near the center of the sample, while Fig. 3(b) shows an area from the end of the sample which reached the highest temperature during the anneal. The effect of the temperature gradient across the sample may be observed. The oxide desorption is at an early stage in the area shown in Fig. 3(a). The OFRs are still generally isolated, with very few adjacent voids overlapping. In contrast, the desorption has progressed to a later stage in the area shown in Fig. 3(b), where there is a greater density of OFRs and many examples of coalescence of neighboring voids. It is important 

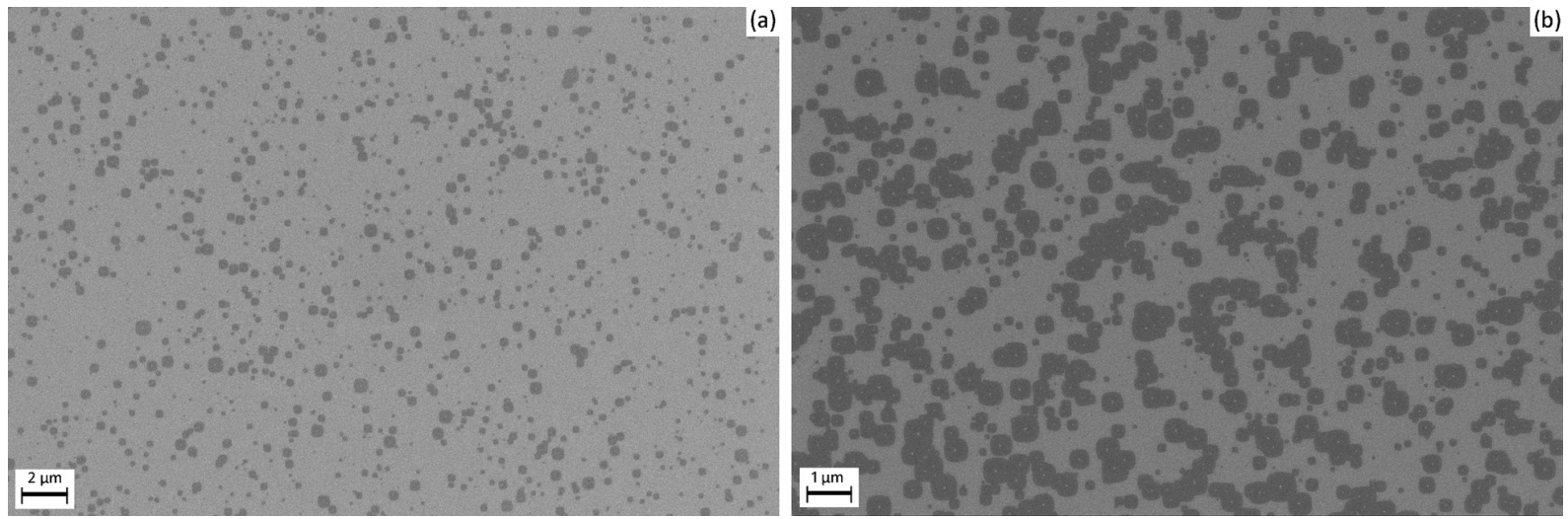

FIG. 3. SEM images of a $50 \mathrm{~nm}$ SOI sample after ten anneal cycles at $750^{\circ} \mathrm{C}$, each lasting $30 \mathrm{~s}$. (a) A region near the center of the sample, and (b) a region near the end of the sample that reached the highest temperature.

to note that this is the latest stage of oxide desorption present on this sample; nowhere on the sample is the oxide completely desorbed, as is seen in Fig. 2(f). Hence, the anneal duration is a significant factor, as ten $30 \mathrm{~s}$ anneal cycles at $750^{\circ} \mathrm{C}$ are not sufficient to fully desorb the oxide.

Figure 4 shows SEM images measured from a sample after ten cycles of annealing at $750{ }^{\circ} \mathrm{C}$ for $90 \mathrm{~s}$. Figures 4 (a) and $4(\mathrm{~b})$ show regions close to the center of the sample, but are representative of the entire surface. At these anneal conditions, the effect of the thermal gradient is no longer significant, as oxide has been desorbed at every point of the sample. Figure 4(a) was recorded at a lower magnification, to show that no large areas of oxide were present in approximately $150 \mu \mathrm{m}^{2}$ of the sample. Similar to the area shown in Fig. 2(f), small protrusions remain on the surface. Figure 4(b) was recorded at higher magnification to allow the irregular and approximately linear shape of these protuberances to be more easily discerned. It is clear that ten $90 \mathrm{~s}$ anneal cycles at $750{ }^{\circ} \mathrm{C}$ are sufficient for the oxide desorption to progress to completion. Hence, it is possible to remove oxide from SOI at temperatures below $800^{\circ} \mathrm{C}$ without causing dewetting of the film; however, the surface displays a significant number of protrusions. The nature of these protrusions and a method of reducing the amount of protrusions present on the surface is discussed below.
In order to see whether a longer duration anneal at a lower temperature is effective at desorbing the oxide layer, a sample was annealed at $690^{\circ} \mathrm{C}$ continuously for $1 \mathrm{~h}$ (Fig. 5). The temperature gradient still plays a significant role, even for this longer anneal. At the end of the sample which reached the lowest temperature, no OFRs were observed at all (SEM image not shown). Figure 5(a) shows a region near the center of the sample. OFRs have nucleated and started to grow, but the observed density of voids indicates a very early stage in the oxide desorption process. The desorption has progressed further along at the end of the sample exposed to higher temperature, shown in Fig. 5(b), but is still at quite an early stage, with neighboring OFRs just beginning to overlap and coalesce. Hence, the anneal temperature is very important. If the temperature is not sufficiently high, significant amounts of oxide will not be desorbed, even after annealing for long durations.

Figures 5(c) and 5(d) show an area near the edge of the sample, recorded at different magnifications. It can be seen that oxide desorption is more prevalent near the edge, as evidenced by both a greater density of OFRs and increased coalescence of adjacent voids. This influence of the film edge is also observed for the dewetting phenomenon, discussed below, where the film edge is modeled as an infinitely long discontinuity from which voids can propagate. ${ }^{12} \mathrm{~A}$
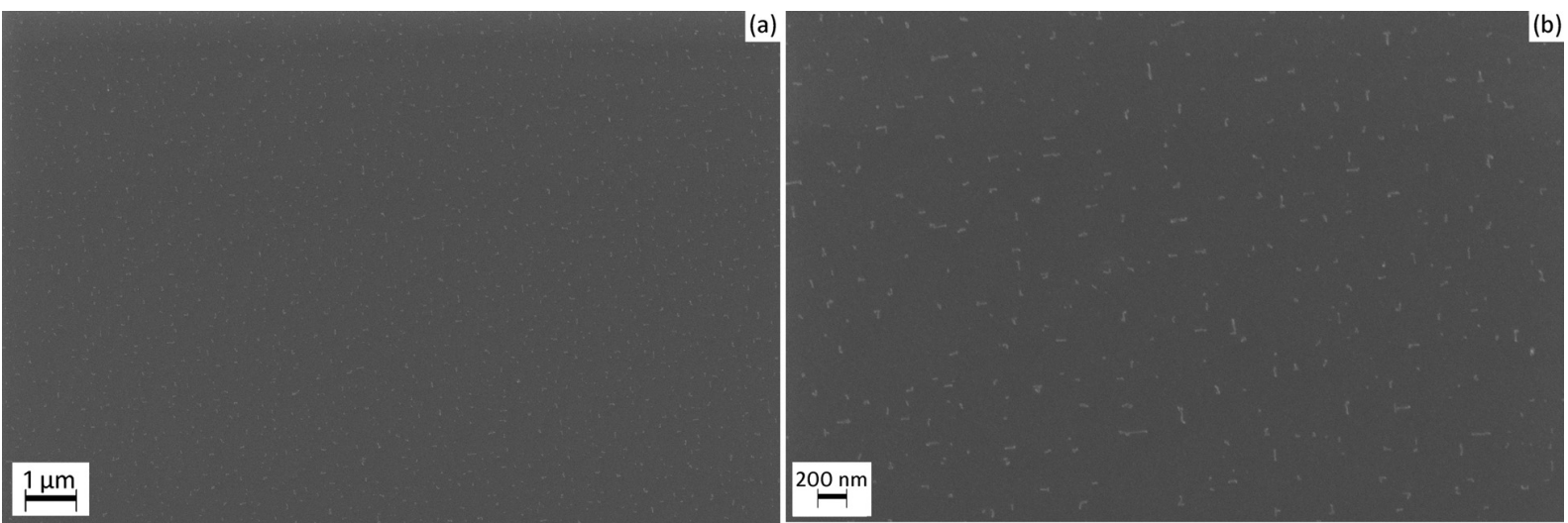

FIG. 4. SEM images of a $50 \mathrm{~nm}$ SOI sample after ten cycles of annealing at $750^{\circ} \mathrm{C}$, each for a duration of $90 \mathrm{~s}$. (a) and (b) Regions near the center of the sample. 

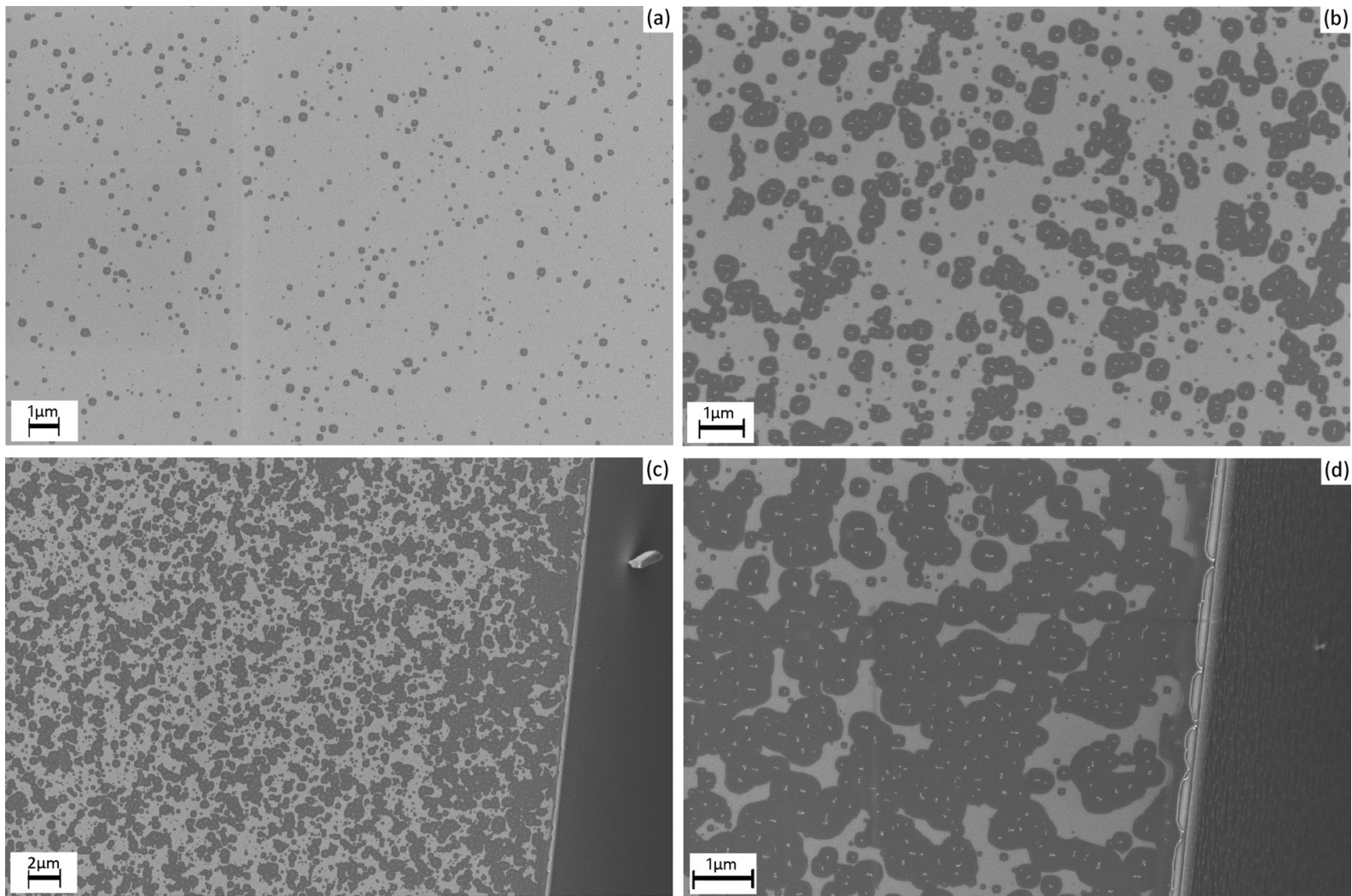

FIG. 5. SEM data for a $50 \mathrm{~nm}$ SOI sample annealed at $690^{\circ} \mathrm{C}$ for $60 \mathrm{~min}$. (a) A region near the center of the sample, and (b)-(d) Areas at the end of the sample that reached the highest temperature.

similar explanation is proposed for the edge effect observed in Figs. 5(c) and 5(d).

In the area shown in Fig. 5(d), the oxide desorption has reached a stage where adjacent OFRs are beginning to overlap, but the shape of the original voids is still discernible. At this resolution, it can be seen that the protrusions located at the center of the OFRs are approximately linear in shape. These structures were previously assigned to carbides ${ }^{3,8,22,23}$ and were proposed to act as nucleation sites for the voids. ${ }^{22}$ These protrusions appear very similar in morphology to those observed after the oxide has been desorbed, suggesting that the protuberances shown in Figs. 2(f) and 4(b) are the carbides still present on the surface. XPS results presented below show evidence for the presence of $\mathrm{SiC}$ on the surface following thermal treatment.

It has been shown above (Fig. 4) that ten $90 \mathrm{~s}$ anneal cycles at $750{ }^{\circ} \mathrm{C}$ is sufficient to completely desorb oxide from the SOI device layer. The effects of a longer anneal at this temperature were investigated by annealing a sample at $750^{\circ} \mathrm{C}$ for $10 \mathrm{~min}$. However, dewetting of the device layer was observed to occur, indicating the necessity of using shorter anneal times and multiple cycles.

\section{B. Dewetting of the Si device layer}

Dewetting of SOI samples with thinner device layers was investigated. Figure 6 shows SEM data measured from SOI samples with device layer thickness of approximately $25 \mathrm{~nm}$ following three $60 \mathrm{~s}$ anneal cycles at $900{ }^{\circ} \mathrm{C}$. The thinner a film, the more likely it is to dewet at a given temperature. ${ }^{12}$ In addition, a given film is more likely to dewet at a higher temperature; therefore, annealing thinner films at $900{ }^{\circ} \mathrm{C}$ encourages dewetting. Figure 6(a) shows a large scale view of an area where dewetting has occurred. The Si film has become broken in places, agglomerating into $\mathrm{Si}$ islands and exposing the BOX layer. The dewetted regions have an approximately circular shape. ${ }^{12,15}$ A closer view of one dewetted region is shown in Fig. 6(b). According to Danielson's five-step model of the dewetting mechanism, ${ }^{12}$ fingers of $\mathrm{Si}$ form at the void edge and then break into nanoislands via a Rayleigh instability. Some examples of Si fingers which are close to breaking into islands are visible in the area shown in Fig. 6(b). ${ }^{16} \mathrm{~A}$ more detailed image of the nanoislands is shown in Fig. 6(c). The Si device layer, exposed BOX, and $\mathrm{Si}$ nanoislands are indicated in the figure. Faceting of the islands can be observed, caused by the facets of the $\mathrm{Si}(100)$ device layer. ${ }^{14,18}$ The nanoislands are usually situated on or beside a region of exposed BOX. The effect of the film edge can be seen in the area shown in Fig. 6(d), where dewetting has occurred along the edge of the sample. This is predicted by Danielson's model. ${ }^{12}$ A void forms around a discontinuity in the film. Whether this void spontaneously closes or begins to grow depends on its size. If the void dimensions exceed a critical radius specific to each film, the void will begin to expand and dewetting will occur, exposing the underlying oxide. The film edge can be considered as a void of infinite 


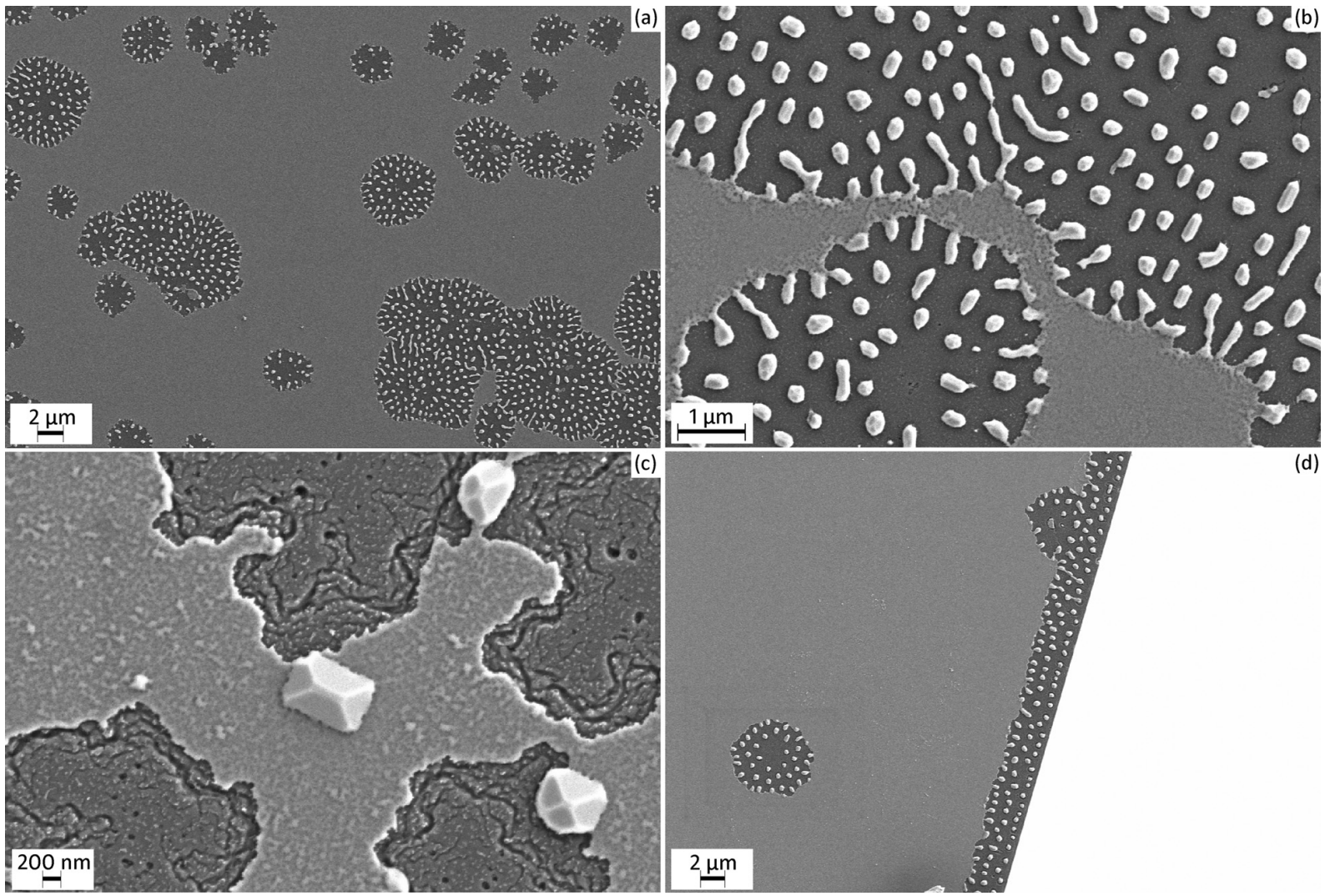

FIG. 6. SEM images showing dewetting of the SOI device layer for $25 \mathrm{~nm}$ samples.

radius; therefore, dewetting will occur along the edge of the device layer, as seen in Fig. 6(d). ${ }^{12}$

\section{Compositional analysis}

Figure 7 shows the Si 2 p core level XPS data measured for a pristine sample [Fig. 7(a)] and a sample twice flashed at $900{ }^{\circ} \mathrm{C}$ for $10 \mathrm{~s}$ [Fig. 7(b)]. The main feature in the spectrum recorded at $10^{\circ}$ (near-normal incidence) for the pristine sample [Fig. $7(a)]$ is fitted with a Voigt doublet at a $2 p_{3 / 2}$ binding energy of $99.7 \pm 0.1 \mathrm{eV}$, with a spin-orbit splitting of $0.6 \mathrm{eV} \cdot{ }^{24,25}$ An additional component at a binding energy of $103.9 \pm 0.1 \mathrm{eV}$ is fitted with a Voigt lineshape and is assigned to $\mathrm{Si}$ in the +4 oxidation state, i.e., in the $\mathrm{SiO}_{2}$ chemical environment. ${ }^{24,26}$ Voigt lineshapes with binding energies of $100.7 \pm 0.1,101.5 \pm 0.1$, and $102.9 \pm 0.1 \mathrm{eV}$ are assigned to $\mathrm{Si}$ in the $+1,+2$, and +3 oxidation states corresponding to the $\mathrm{Si}_{2} \mathrm{O}, \mathrm{SiO}$, and $\mathrm{Si}_{2} \mathrm{O}_{3}$ suboxides, respectively; ${ }^{24,26,27}$ however, the contributions from $\mathrm{Si}^{2+}$ and $\mathrm{Si}^{3+}$ are negligible at near-normal incidence. The contributions from $\mathrm{Si}$ in the $+1,+2$, and +3 oxidation states increase as the angle between the surface normal and the analyzer is increased to $40^{\circ}$ [Fig. 7(a)]. These chemical environments also contribute to the spectrum recorded at grazing incidence $\left(70^{\circ}\right)$. It is observed that the overall signal in the $\mathrm{Si} 2 \mathrm{p}$ region decreases dramatically as the measurement angle moves from near-normal to grazing incidence, i.e., as the surface sensitivity increases. For data recorded at $40^{\circ}$ and $70^{\circ}$, the signal-to-noise ratio is significantly lower than for data measured at $10^{\circ}$, and it was necessary to multiply the $40^{\circ}$ and $70^{\circ}$ data by a factor of 10 in order to display the spectra on one scale, as noted in Fig. 7(a). This indicates that a thick layer of oxide is present on the pristine sample, which has the effect of attenuating the Si 2 p signal as the measurement becomes increasingly surface sensitive. In addition, the
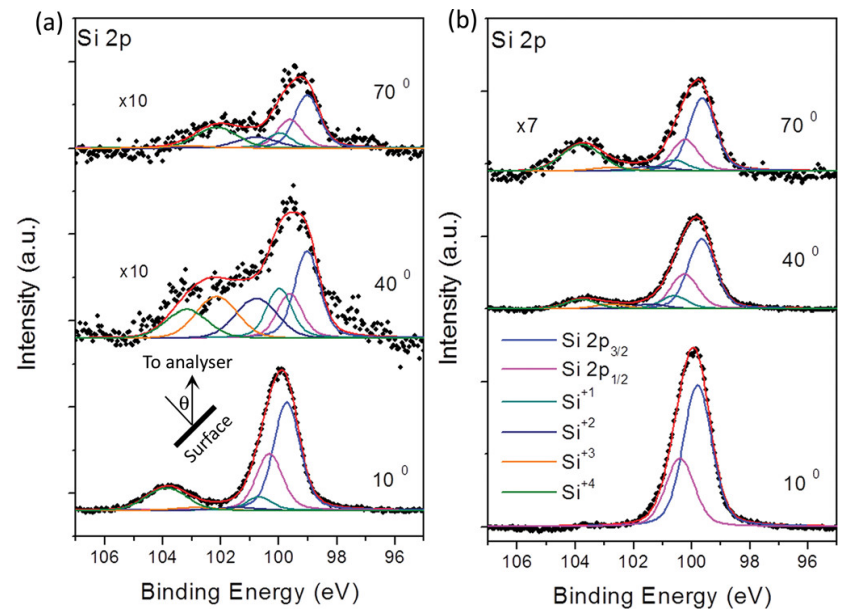

FIG. 7. (Color online) XPS measurements showing the Si $2 p$ core level for (a) pristine and (b) flashed (two anneal cycles at $900^{\circ} \mathrm{C}$ for $10 \mathrm{~s}$ ) SOI recorded at different angles of incidence (see inset). Components fitted as follows: $\mathrm{Si} 2 \mathrm{p}_{3 / 2}$ (blue), Si $2 \mathrm{p}_{1 / 2}$ (magenta), $\mathrm{Si}^{+1}$ (dark cyan), $\mathrm{Si}^{+2}$ (navy), $\mathrm{Si}^{+3}$ (orange), and $\mathrm{Si}^{+4}$ (olive). Inset in (a) shows measurement angle $\theta$ with respect to analyzer and surface normal. 
components assigned to $\mathrm{Si}$ in the $+1,+2,+3$, and +4 oxidation states account for over half $(62 \%)$ of the total intensity of the spectra measured at $40^{\circ}$ and $70^{\circ}$, confirming the presence of a thick oxide layer.

In the case of the sample flashed for two anneal cycles at $900{ }^{\circ} \mathrm{C}$ for $10 \mathrm{~s}$ [Fig. 7(b)], the Si 2p signal is dominated by the doublet with $2 \mathrm{p}_{3 / 2}$ binding energy of $99.8 \pm 0.1 \mathrm{eV}$ and a spin-orbit splitting at $0.6 \mathrm{eV} .{ }^{24-26}$ For near-normal incidence $\left(10^{\circ}\right)$, there is a negligible contribution from $\mathrm{Si}$ in oxidation states related to the formation of silicon suboxides. As the measurement angle increases to $40^{\circ}$, the signal does not show the marked attenuation of intensity observed for the analogous spectrum recorded from the pristine sample. However, there is an attenuation of the Si $2 p$ signal for grazing incidence, requiring the data to be multiplied by a factor of 7 in order to display all three spectra on one scale. The contributions from $\mathrm{Si}$ atoms in the suboxide chemical environments $\left(\mathrm{Si}_{2} \mathrm{O}, \mathrm{SiO}\right.$, and $\left.\mathrm{Si}_{2} \mathrm{O}_{3}\right)$ remain negligible at $70^{\circ}$. However, there is a significant contribution from $\mathrm{Si}$ in the +4 oxidation state, assigned to the $\mathrm{SiO}_{2}$ chemical environment. ${ }^{24,26}$ As the signal from silicon in the $\mathrm{SiO}_{2}$ environment can only be detected by XPS at grazing incidence, this indicates the presence of a very thin oxide layer on the surface. This is most likely unavoidable in the case of ex situ XPS measurements, even taking into account the short turnaround time of $20 \mathrm{~min}$.

Angle-dependent XPS data were also recorded for the C $1 \mathrm{~s}$ region, in an attempt to elucidate the character of the protrusions observed at the center of OFRs (Figs. 2-5). For measurements recorded from the pristine sample at nearnormal incidence [Fig. 8(a)], a weak signal is observed in the $\mathrm{C} 1 \mathrm{~s}$ region. The spectrum was fitted with two Voigt lineshapes at binding energies of $284.2 \pm 0.1$ and $285.2 \pm 0.1 \mathrm{eV}$, assigned to $\mathrm{C}-\mathrm{Si}$ and $\mathrm{C}-\mathrm{C}$, respectively. ${ }^{28}$ For the spectrum recorded at $40^{\circ}$, the overall intensity has increased, and a third feature at $287.9 \pm 0.1 \mathrm{eV}$ binding energy is present, assigned to $\mathrm{C}=\mathrm{O} .^{29}$ The main contribution comes from
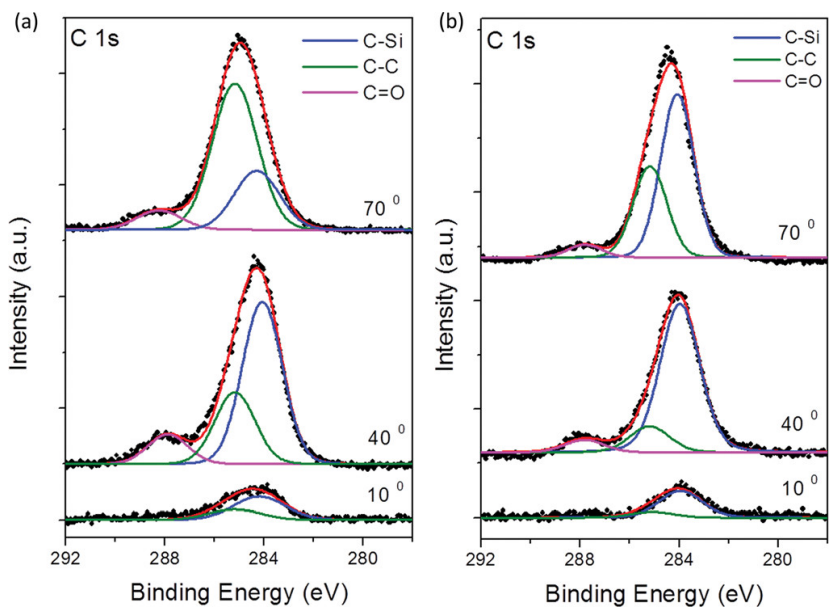

FIG. 8. (Color online) XPS measurements showing the C 1 s core level for (a) pristine and (b) flashed (two anneal cycles at $900{ }^{\circ} \mathrm{C}$ for $10 \mathrm{~s}$ ) recorded at different angles of incidence. Components fitted as follows: C-Si (blue), C$\mathrm{C}$ (olive), and $\mathrm{C}=\mathrm{O}$ (magenta). carbon bonded to silicon, which accounts for $62 \%$ of the overall C 1 s signal, compared to $27 \%$ for C-C. At grazing incidence, the inverse relationship is observed, with the $\mathrm{C}-\mathrm{C}$ contribution accounting for $65 \%$ of the total signal, compared to $26 \%$ for C-Si [Fig. 8(a)]. This indicates that for the pristine sample, while a proportion of carbon is interacting with silicon, carbon bonding exclusively with other carbon atoms is the dominant species.

Figure 8(b) shows XPS data for the $\mathrm{C} 1 \mathrm{~s}$ region recorded after flashing the sample twice at $900^{\circ} \mathrm{C}$ for $10 \mathrm{~s}$. At each measurement angle, the total $\mathrm{C} 1 \mathrm{~s}$ signal is comparable to that measured for the pristine sample [Fig. 8(a)], indicating that sample processing has not resulted in significant carbon contamination. It is observed that for the flashed sample, the contribution from carbon bonded to silicon is the main component at each measurement angle [Fig. 8(b)]. This is in contrast to the spectra measured from the pristine sample [Fig. 8(a)]. For data recorded at $40^{\circ}$ and $70^{\circ}$ for the flashed sample [Fig. 8(b)], the C-Si contribution accounts for $79 \%$ and $61 \%$, respectively, of the total signal. Hence, even at maximum surface sensitivity, the majority of the carbon present is interacting with silicon. The data presented in Fig. 8 indicate that the total amount of carbon present is not significantly altered by flashing the sample; however, thermal treatment does have an effect on the chemical composition of the carbon, leading to a greater chemical interaction with $\mathrm{Si}$. While this XPS data does not preclude the protrusions observed at the center of OFRs from being oxide islands, it is evidence that $\mathrm{SiC}$ is present on the surface following annealing, which supports the conjecture that the protrusions are SiC islands. $^{22}$

Tapping mode AFM was utilized to further investigate the nature of the protrusions observed on the Si device layer following removal of the native oxide. Tapping mode AFM can measure ultralow forces with high spatial resolution without significant influences of tip-sample contact adhesion and capillary effects by adsorbed water layer. Tip-surface adhesion can be further reduced by the use of a stiff AFM cantilever tip, and the resulting phase contrast images are highly sensitive to the relative variation in local stiffness of the sample. It is known from the literature that for a stiff cantilever tip where the effect of adhesion is negligible, phase shift is predominantly influenced by the elastic modulus inhomogeneity in the sample surface. ${ }^{30}$ The nature of the inhomogeneity can be explained quantitatively with the help of additional information supplied by other analyses. Combining chemical analyses with AFM phase contrast imaging, it is possible to identify relative variation in the stiffness of the surface. ${ }^{30}$ Hence, this technique is suitable for probing the stiffness of the protrusions relative to the native oxide and the device layer.

AFM topography and phase contrast imaging is adopted in this work to study the annealing temperature related oxide desorption process, formation of SiC structures and its spatial distribution. A stiff cantilever tip with resonance frequency of $300 \mathrm{kHz}$ was used for all AFM measurements. Figures 9(a)-9(d) show topography and phase contrast images measured across the sample of a $50 \mathrm{~nm}$ SOI after ten 

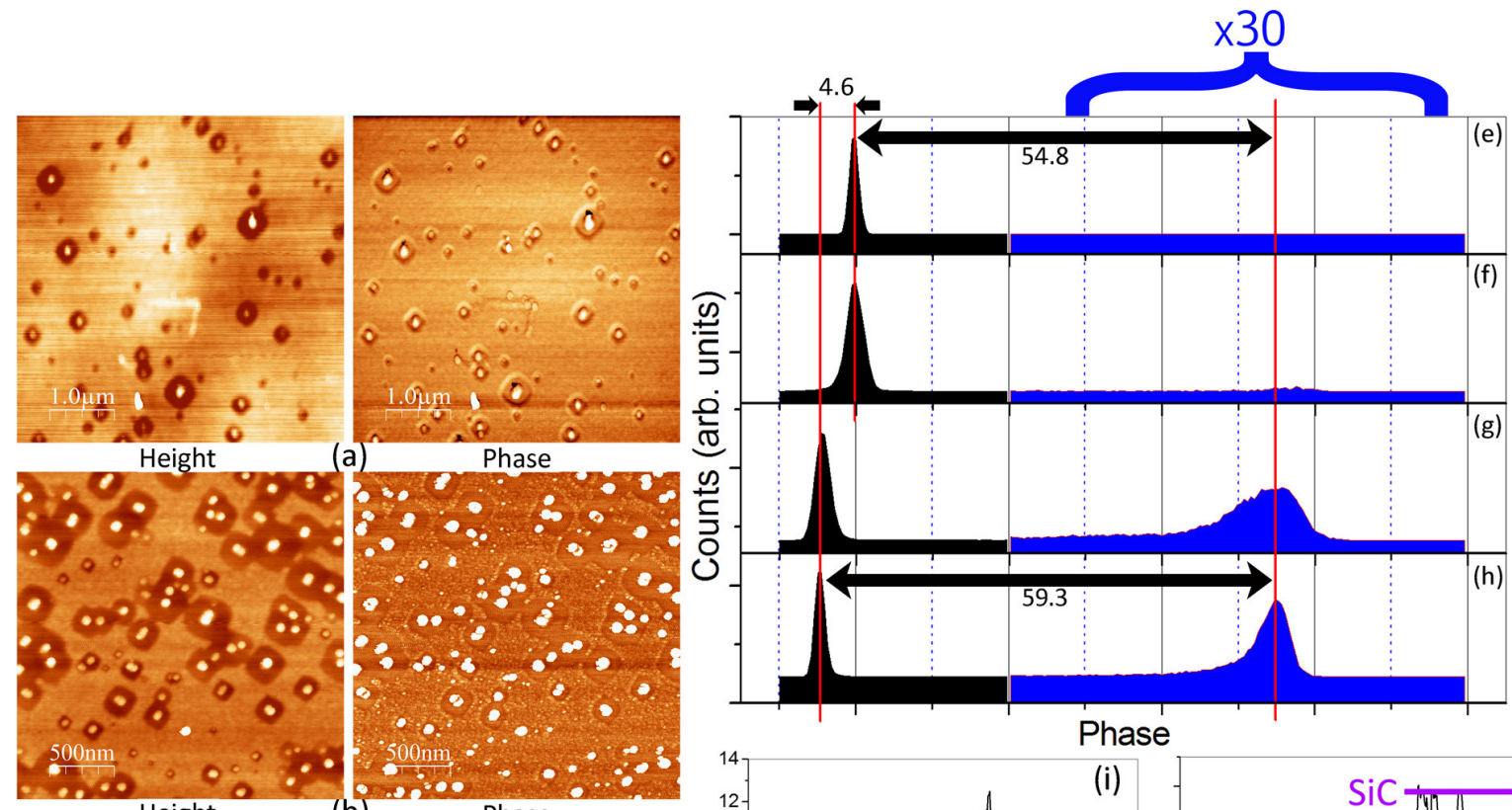

(a)
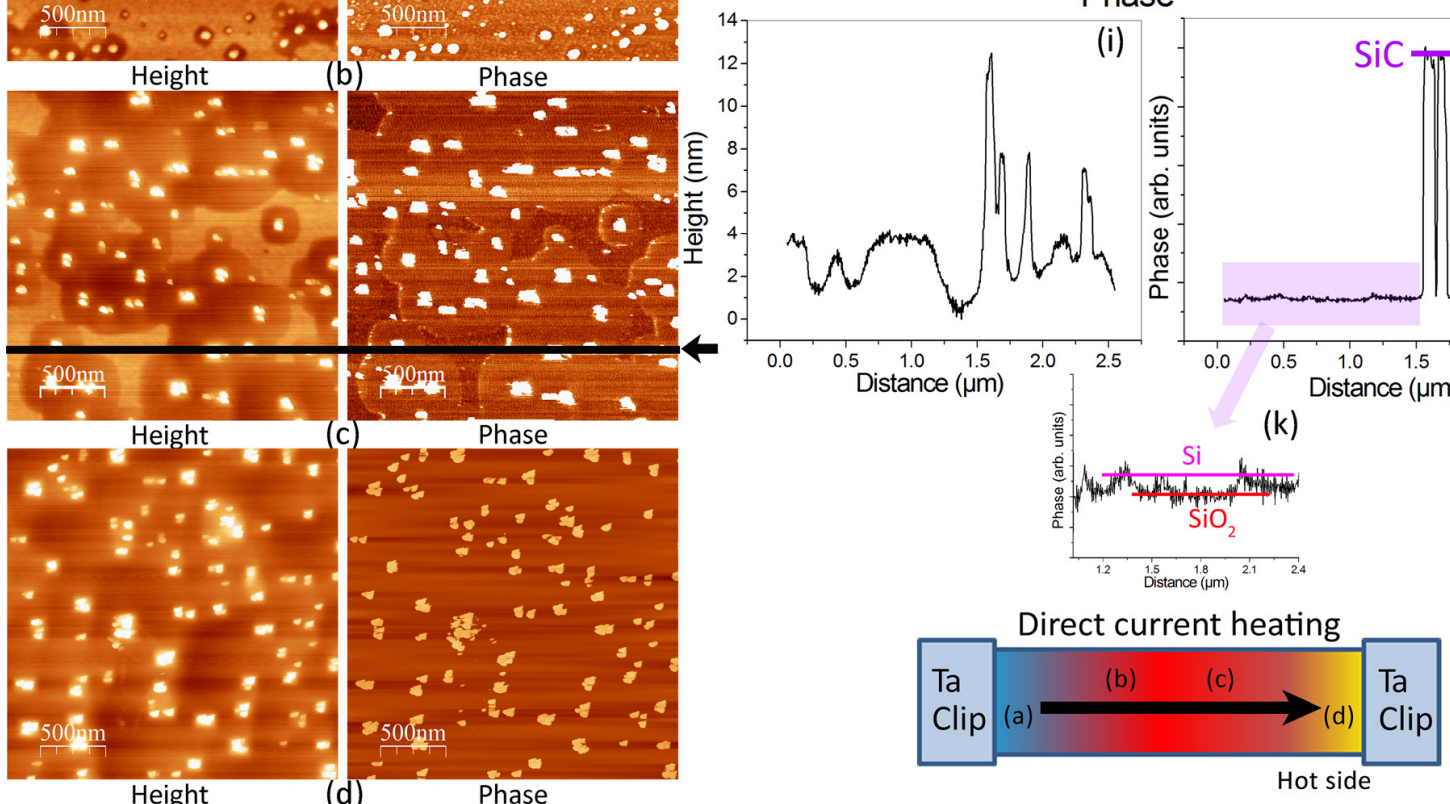

FIG. 9. (Color online) Topography and phase contrast AFM images measured across a $50 \mathrm{~nm}$ SOI sample after 10 anneal cycles at $750^{\circ} \mathrm{C}$, each lasting $60 \mathrm{~s}$. Oxide desorption process is captured at different stages (a)-(d) due to thermal gradient across the sample as indicated by (l). (e) Phase histogram for a surface covered fully with oxide and (f)-(h) phase histogram for (a), (b), and (d), respectively. (i) and (j) Height and phase line profile across the line indicated in (c). (k) The zoom in of the phase profile indicated by the red box.

anneal cycles at $750^{\circ} \mathrm{C}$, each lasting $60 \mathrm{~s}$. Different stages of oxide desorption and distribution of the protrusions have been recorded due to the thermal gradient across the sample.

Figure 9(a) shows an early stage of oxide desorption, where a small number of OFRs are present on the surface while Fig. 9(d) shows complete desorption of oxide and high density of protrusions. The protrusions at the center of each OFR are clearly visible in both height images and phase contrast images [Figs. 9(a)-9(d)]. Height and phase line profiles shown in Figs. 9(i) and 9(j), taken across the line shown in Fig. 9(c), show a clear phase angle distinction between the protrusions and the silicon device layer [Fig. 9(j)], while a minor phase contrast can be seen between the silicon and the oxide [Fig. 9(k)]. The phase histograms in Figs. 9(e)-9(h) shows the distribution of phase angle for the phase contrast images. Figure $9(\mathrm{e})$ is from a sample with native oxide before thermal treatment. Figures 9 (f) -9 (h) are the phase histograms corresponding to Figs. 9(a), 9(b), and 9(d), respectively. The intensity of the peak on the right, shown in blue, has been multiplied 30 times in order to plot it on the same scale as the peak on the left, shown in black. The location of the peak on the left changes as the area of oxide and silicon coverage varies in the image, with a $4.6^{\circ}$ phase difference apparent between Fig. 9(e), corresponding to a sample fully covered with oxide and Fig. 9(h), recorded after all oxides have been removed, leaving the silicon device layer and a high density of protrusions, as seen in Fig. 9(d). In addition, the intensity of the peaks on the right gradually increases 
from Figs. 9(e) to 9(h). These observations indicate that the two peaks on the left are the contributions of oxide and silicon while the peak on the right is a contribution from the protrusions and is shifted from the peaks relating to oxide and silicon by about $54.8^{\circ}$ and $59.3^{\circ}$, respectively. Topography and phase contrast AFM measurements indicate that the protrusions observed on the surface following oxide desorption are stiffer than the surrounding oxide-free regions and $\mathrm{Si}$ device layer. These relative stiffnesses agree well with the literature. ${ }^{30,31}$ This AFM data, together with XPS data showing the presence of carbon bonded to $\mathrm{Si}$ on the surface of the SOI [Fig. 8(b)], support the hypothesis that these protrusions are $\mathrm{SiC}$.

Since there must be a nucleation site for each OFR in order to begin the creation of Si monomers which can then react with $\mathrm{SiO}_{2}$ to form volatile $\mathrm{SiO}$, the location of the $\mathrm{SiC}$ protrusions at the center of each OFR suggests that they may be the nucleation sites for the decomposition of the $\mathrm{SiO}_{2}{ }^{22}$ One possible nucleation mechanism is a reaction between carbon impurities and $\mathrm{SiO}_{2}$ to form $\mathrm{SiC}$, which can then react with $\mathrm{SiO}_{2}$ to form gaseous $\mathrm{SiO}$, according to the following equations: ${ }^{32}$

$$
\begin{aligned}
& \mathrm{SiO}_{2}+3 \mathrm{C}=\mathrm{SiC}+2 \mathrm{CO}, \\
& 2 \mathrm{SiO}_{2}+\mathrm{SiC}=3 \mathrm{SiO}+\mathrm{CO} .
\end{aligned}
$$

The volatile $\mathrm{SiO}$ desorbs and the void begins to open in the oxide around the $\mathrm{SiC}$ site; thereafter, the void growth occurs via the process described above. It is known from the literature that the formation temperature of a thin layer of $\mathrm{SiC}$ on silicon is approximately $650{ }^{\circ} \mathrm{C} ; ;^{33}$ when the temperature is increased to $750-800^{\circ} \mathrm{C}, \mathrm{SiC}$ islands form. ${ }^{34}$ The thermal treatment used in this experiment is sufficient to result in $\mathrm{SiC}$ islands.

\section{Elimination of surface carbide and STM analysis}

A clean Si surface is crucial for device fabrication, epitaxial growth, and surface studies. The thermal process presented above results in the removal of oxide without loss of integrity of the device layer; however, it would be advantageous to reduce the number of $\mathrm{SiC}$ protrusions present on the device layer after annealing. Annealed SOI samples were treated ex situ with "Piranha" solution (4:1 concentration solution of sulfuric acid and hydrogen peroxide) followed by RCA solution (1:1:5 concentration solution of ammonium hydroxide, hydrogen peroxide, and water). ${ }^{35}$ While this process can result in a clean surface for UHV surface measurements, ${ }^{1}$ it is essential to maintain the highest clean-room standards and use ultrapure electronic grade chemicals during the process. Failing to maintain the highest standards during the cleaning process may lead to a contaminated ${ }^{35}$ and rough $\mathrm{Si}$ surface. These restrictions make the cleaning process time-consuming and expensive.

A simple yet effective oxygen plasma-based cleaning process has been developed to obtain atomically clean and
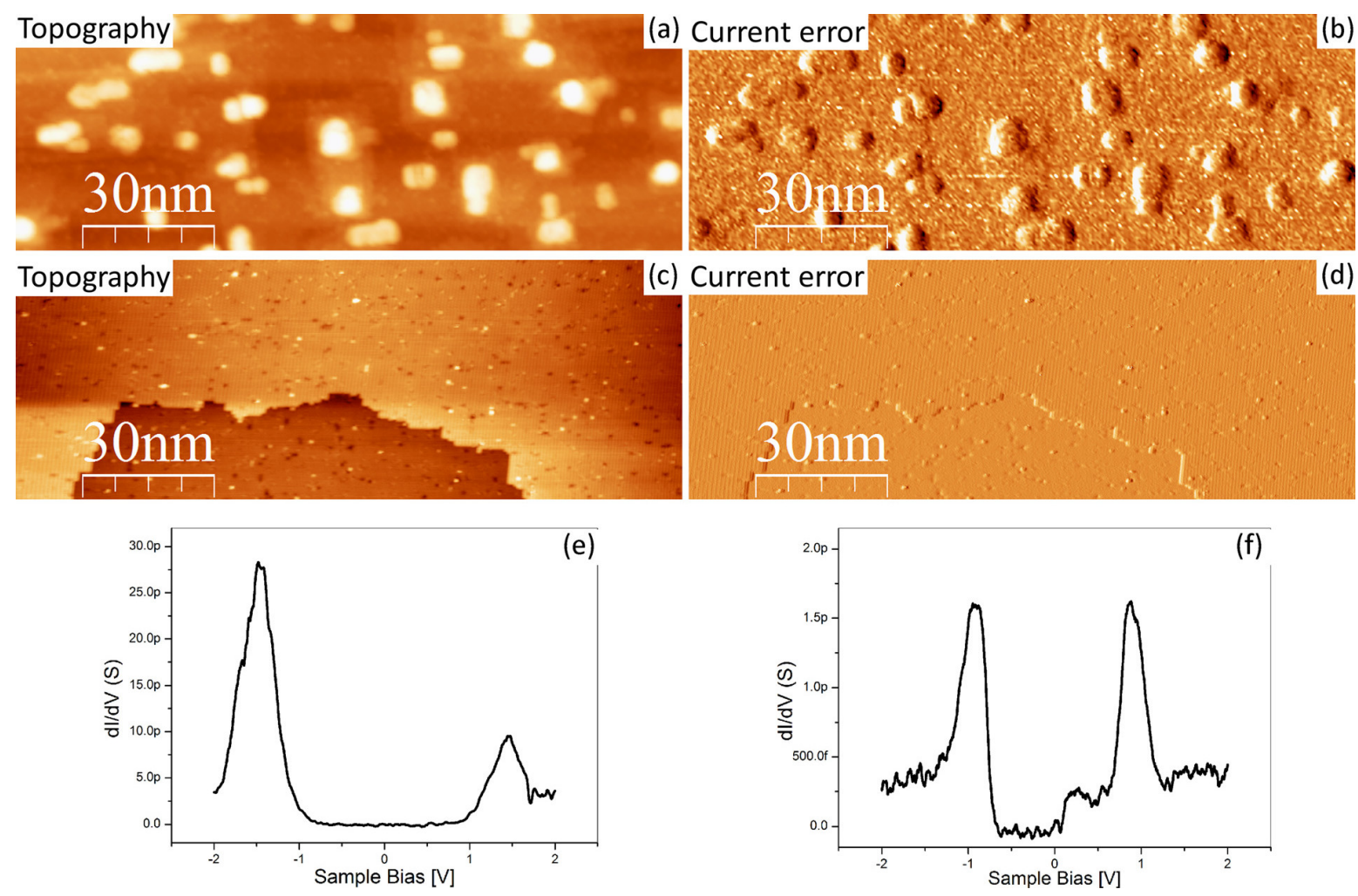

FIG. 10. (Color online) Topography (a) and current error (b) STM images of a pristine $50 \mathrm{~nm}$ SOI sample after 10 anneal cycles at $750{ }^{\circ} \mathrm{C}$, each lasting $90 \mathrm{~s}$. Topography (c) and current error (d) STM images of $30 \mathrm{~s}$ oxygen plasma cleaned $47 \mathrm{~nm}$ SOI sample annealed with the same parameters as above. All STM image dimensions are $150 \times 54 \mathrm{~nm}$ and imaging set points (a) and (b): $3 \mathrm{~V}, 5 \mathrm{pA}$; (c) and (d): $2 \mathrm{~V}, 20 \mathrm{pA}$; (e) and (f) STS recorded on a SiC protrusion and on $\mathrm{Si}$ device layer of SOI following the $30 \mathrm{~s}$ oxygen plasma cleaning, respectively. 
smooth surfaces. Pristine $50 \mathrm{~nm}$ SOI samples were exposed to an oxygen plasma in an ICP system for $30 \mathrm{~s}$, followed by a $60 \mathrm{~s}$ dip in dilute hydrogen fluoride $(\mathrm{HF})$ and were finally rinsed in water for $30 \mathrm{~s}$. The oxygen plasma oxidizes carbon contaminants and leaves a layer of oxide on the silicon surface, while the HF rinse strips off the oxide grown in the plasma chamber. Samples were then passivated with oxygen by rinsing briefly in $\mathrm{H}_{2} \mathrm{O}_{2}$ solution before loading into the UHV chamber.

An SOI sample was cleaned using the ex situ oxygen plasma based process described above, before being loaded into a UHV chamber in preparation for LT-STM. The sample was annealed once at $750^{\circ} \mathrm{C}$ for $60 \mathrm{~s}$. Figure 10 shows STM data measured from the resultant surface. It can be seen that this single $750{ }^{\circ} \mathrm{C}$ anneal cycle was sufficient to desorb all oxide. This is due to the $\mathrm{H}_{2} \mathrm{O}_{2}$ rinse after oxygen plasma cleaning and oxide stripping in dilute HF solution that leaves a very thin layer of oxide on the device layer which is readily desorbed with a short anneal. Figure 10 shows topography and current error images of a pristine $50 \mathrm{~nm}$ SOI and a plasma-cleaned $47 \mathrm{~nm}$ SOI. The bright regions seen in the topographical data for the pristine sample [Fig. 10(a)] are the $\mathrm{SiC}$ protrusions. These protrusions can clearly be seen on the current error image [Fig. 10(b)]. There is a marked difference in the number of protrusions on the plasma-cleaned samples compared to the pristine samples. Figure 10(e) shows the scanning tunneling spectra (STS) recorded on a $\mathrm{SiC}$ protrusion. The band gap of the $\mathrm{SiC}$ structures was observed to be around $2 \mathrm{eV}$, similar to the value reported in the literature. ${ }^{22,36}$ A STM height and current error images for a cleaned $47 \mathrm{~nm}$ SOI are shown in Figs. $10(\mathrm{c})$ and $10(\mathrm{~d})$, respectively, along with the STS spectra recorded on the clean Si surface is shown Fig. 10(f) for the comparison.

\section{CONCLUSIONS}

Oxide desorption from SOI in UHV conditions without dewetting of the device layer is a challenge due to its dependency on both anneal temperature and duration. Different anneal procedures were investigated in order to find an effective low thermal budget process and the mechanism of desorption at different stages of oxide removal were studied in individual samples by means of a thermal gradient of $\sim 50^{\circ} \mathrm{C}$ across the sample. Ten $90 \mathrm{~s}$ anneal cycles at $750^{\circ} \mathrm{C}$ were found to remove oxide from the entire sample; however, the surface protrusion that act as nucleation sites for desorption remained. XPS measurements performed on pristine and flashed samples confirm the removal of a thick oxide layer during thermal treatment, and indicate that carbon present on the sample remains on the surface during annealing. The chemical composition of the carbon is altered, resulting in increased interaction between carbon and silicon and the formation of silicon carbide. These SiC protrusions on the annealed oxide-free pristine samples are likely formed due to the presence of carbon contaminants on the SOI surface during the annealing process. A simple oxygen plasma cleaning followed by HF etching carried out before in situ annealing can reduce the $\mathrm{SiC}$ protrusions substantially, resulting in an atomically smooth SOI surface. A simple low thermal budget annealing process has been developed to produce an atomically clean and oxide free SOI surface without dewetting.

\section{ACKNOWLEDGMENT}

This work was supported by Science Foundation Ireland under PI Award Grant Nos. 12/IA/1482 and CRANN.

${ }^{1}$ P. Zhang, E. Tevaarwerk, B. N. Park, D. E. Savage, G. K. Celler, I. Knezevic, P. G. Evans, M. A. Eriksson, and M. G. Lagally, Nature 439, 703 (2006); P. Sutter, W. Ernst, and E. Sutter, Appl. Phys. Lett. 85, 3148 (2004).

${ }^{2}$ G. K. Celler and S. Cristoloveanu, J. Appl. Phys 93, 4955 (2003); R. H. Yan, A. Ourmazd, and K. F. Lee, IEEE Trans. Electron Devices 39, 1704 (1992).

${ }^{3}$ K. Xue, J. B. Xu, and H. P. Ho, Nanotechnology 18, 485709 (2007).

${ }^{4}$ H. Hibino, M. Uematsu, and Y. Watanabe, J. Appl. Phys. 100, 113519 (2006).

${ }^{5}$ U. Johansson, H. Zhang, and R. Nyholm, J. Electron. Spectrosc. Relat. Phenom. 84, 45 (1997); Y. K. Sun, D. J. Bonser, and T. Engel, Phys. Rev. B 43, 14309 (1991); Y. K. Sun, J. Vac. Sci. Technol., A 10, 2314 (1992); S. Ogawa, A. Yoshigoe, S. Ishidzuka, Y. Teraoka, and Y. Takakuwa, Thin Solid Films 508, 169 (2006).

${ }^{6}$ R. Tromp, G. W. Rubloff, P. Balk, F. K. LeGoues, and E. J. van Loenen, Phys. Rev. Lett. 55, 2332 (1985).

${ }^{7}$ K. E. Johnson and T. Engel, Phys. Rev. Lett. 69, 339 (1992).

${ }^{8}$ D. Jones and V. Palermo, Appl. Phys. Lett. 80, 673 (2002).

${ }^{9}$ I. Kinefuchi, H. Yamaguchi, Y. Sakiyama, S. Takagi, and Y. Matsumoto, J. Chem. Phys. 128, 164712 (2008)

${ }^{10}$ M. Liehr, J. E. Lewis, and G. W. Rubloff, J. Vac. Sci. Technol., A 5, 1559 (1987).

${ }^{11}$ E. Bussmann, F. Cheynis, F. Leroy, and P. Müller, IOP Conf. Ser.: Mater. Sci. Eng. 12, 012016 (2010).

${ }^{12}$ D. T. Danielson, D. K. Sparacin, J. Michel, and L. C. Kimerling, J. Appl. Phys. 100, 083507 (2006).

${ }^{13}$ E. Bussmann, F. Cheynis, F. Leroy, P. Müller, and O. Pierre-Louis, New J. Phys. 13, 043017 (2011); B. Legrand, V. Agache, J. P. Nys, V. Senez, and D. Stievenard, Appl. Phys. Lett. 76, 3271 (2000).

${ }^{14}$ B. Yang, P. Zhang, D. E. Savage, M. G. Lagally, G. Lu, M. Huang, and F. Liu, Phys. Rev. B 72, 235413 (2005).

${ }^{15}$ B. Legrand, V. Agache, T. Mélin, J. P. Nys, V. Senez, and D. Stiévenard, J. Appl. Phys. 91, 106 (2002); M. Aouassa, L. Favre, A. Ronda, H. Maaref, and I. Berbezier, New J. Phys. 14, 063038 (2012).

${ }^{16}$ F. Leroy, F. Cheynis, T. Passanante, and P. Müller, Phys. Rev. B 85, 195414 (2012).

${ }^{17}$ M. Tabe, M. Kumezawa, T. Yamamoto, S. Makita, T. Yamaguchi, and Y. Ishikawa, Appl. Surf. Sci. 142, 553 (1999).

${ }^{18}$ R. Nuryadi, Y. Ishikawa, and M. Tabe, Appl. Surf. Sci. 159, 121 (2000).

${ }^{19}$ Y. Ota, J. Electrochem. Soc. 126, 1761 (1979).

${ }^{20}$ Y. Wei, R. M. Wallace, and A. C. Seabaugh, Appl. Phys. Lett. 69, 1270 (1996).

${ }^{21}$ N. Miyata, H. Watanabe, and M. Ichikawa, Phys. Rev. Lett. 84, 1043 (2000).

${ }^{22}$ J. Y. Park and R. J. Phaneuf, J. Vac. Sci. Technol., B 21, 1254 (2003).

${ }^{23}$ S. M. Gray, M. K.-J. Johansson, and L. S. O. Johansson, J. Vac. Sci. Technol., B 14, 1043 (1996); D. Dijkkamp, E. J. van Loenen, A. J. Hoeven, and J. Dieleman, J. Vac. Sci. Technol., A 8, 218 (1990); B. S. Swartzentruber, Y.-W. Mo, M. B. Webb, and M. G. Lagally, ibid. 7, 2901 (1989); A. W. Munz, Ch. Ziegler, and W. Göpel, Surf. Sci. 325, 177 (1995).

${ }^{24}$ M. Bhargava, W. Donner, A. K. Srivastava, and J. C. Wolfe, J. Vac. Sci. Technol., B 26, 305 (2008).

${ }^{25}$ F. J. Himpsel, F. R. McFeely, A. Taleb-Ibrahimi, J. A. Yarmoff, and G. Hollinger, Phys. Rev. B 38, 6084 (1988).

${ }^{26}$ M. Y. Bashouti, J. Ristein, H. Haick, and S. Christiansen, Hybrid Mater. 1, 2299 (2013).

${ }^{27}$ G. Hollinger and F. J. Himpsel, J. Vac. Sci. Technol., A 1, 640 (1983). 
${ }^{28}$ R. Bywalez, H. Karacuban, H. Nienhaus, C. Schulz, and H. Wiggers, Nanoscale Res. Lett. 7, 76 (2012); H. Watanabe, K. Fujita, and M. Ichikawa, Appl. Phys. Lett. 70, 1095 (1997); P. Merino et al., Nat. Commun. 5, 3054 (2014).

${ }^{29}$ A. Popescu et al., Materials 8, 3284 (2015).

${ }^{30}$ H. S. Ahn, S. A. Chizhik, A. M. Dubravin, V. P. Kazachenko, and V. V. Popov, Wear 249, 617 (2001).

${ }^{31}$ C. R. Stoldt, M. C. Fritz, C. Carraro, and R. Maboudian, Appl. Phys. Lett. 79, 347 (2001); M. Mehregany, T. Lijun, L. G. Matus, and D. J. Larkin, IEEE Trans. Electron Devices 44, 74 (1997).

${ }^{32}$ K. Sujirote and P. Leangsuwan, J. Mater. Sci. 38, 4739 (2003); R. V. Krishnarao, Y. R. Mahajan, and T. J. Kumar, J. Eur. Ceram. Soc. 18, 147 (1998); E. J. Opila and Q. N. Nguyen, J. Am. Ceram. Soc. 81, 1949 (1998).
${ }^{33}$ T. Suzuki, D. C. Sorescu, and J. T. Yates, Surf. Sci. 600, 5092 (2006).

${ }^{34}$ S. T. Jemander, H. M. Zhang, R. I. G. Uhrberg, and G. V. Hansson, Phys. Rev. B 65, 115321 (2002); K. Miki and K. Sakamoto, Appl. Phys. Lett. 71, 3266 (1997); J. Y. Maeng and S. Kim, Surf. Sci. 482, 1445 (2001).

${ }^{35}$ M. Meuris, P. W. Mertens, A. Opdebeeck, H. F. Schmidt, M. Depas, G. Vereecke, M. M. Heyns, and A. Philipossian, Solid State Technol. 38, 109 (1995), available at https://lirias.kuleuven.be/handle/123456789/67874.

${ }^{36}$ D. A. Bonnell, G. S. Rohrer, and R. H. French, J. Vac. Sci. Technol., B 9 , 551 (1991); Y. Tawada, K. Tsuge, M. Kondo, H. Okamoto, and Y. Hamakawa, J. Appl. Phys. 53, 5273 (1982); F. Demichelis, C. F. Pirri, and E. Tresso, ibid. 72,1327 (1992). 